\title{
The Effects of Aromatherapy on Sleep Quality in Diabetes Patients with Restless Leg Syndrome in Taiwan
}

\author{
Pei-Jung Yu, RN, MSN, PhD candidate \\ National Taipei University of Nursing and Health Sciences, Taiwan (R.O.C.) \\ Ai-Fu Chiou, RN, PhD \\ National Yang-Ming University, Taiwan (R.O.C.)
}

Doi: 10.19044/esj.2018.v14n30p371 URL:http://dx.doi.org/10.19044/esj.2018.v14n30p371

\begin{abstract}
This study is a longitudinal experimental design that examine the effects of aromatherapy on sleep quality in diabetes patients with restless leg syndrome (RLS). Patients in the experimental group received the aromatherapy intervention for 6 weeks, while those in the control group received only regular nursing care. The instruments included Pittsburg Sleep Quality Index and SureStep TM of blood glucose meters. Data were collected at pre-test, 2nd week, 4th week, and 6th week after the aromatherapy. Data analysis included descriptive analysis, chi-square, independent $t$ test, Pearson correlation, repeated measure ANOVA and general linear mixed-effect models. Forty-four diabetes patients with RLS were randomly assigned to the experimental group $(n=22)$ and the control group $(n=22)$ at a hospital in northern Taiwan. Sleep quality of diabetes patients with RLS was poor in this study. Sleep latency of patients in the experimental group was improved at 2nd week after aromatherapy. Subjective sleep quality and sleep disturbance of patients was also improved at 4th week after aromatherapy. At 6th week, patients in the experimental group had increased their sleep duration, and improved their overall sleep quality. The level of blood sugar was decreased at 2 nd week after aromatherapy on experimental group. Based on the analysis it was concluded that Aromatherapy can ameliorate both blood sugar and sleep quality of diabetes patients with RLS. Thus aromatherapy can be a safe, noninvasive, effective approach for clinical nurses as a therapy in routine care to improve sleep quality in diabetes patients with neuropathy.
\end{abstract}

Keywords: Sleep quality, aromatherapy, diabetes, restless leg syndrome 


\section{Introduction}

Sleep disorders are becoming more prevalent, affecting physical and mental health and are considered to be an important part of overall health in our modern society. Sleep disorders may be caused by various medical conditions, mental illnesses and chronic diseases such as diabetes and heart disease. (Talih, Ajaltouni, \& Kobeissy, 2016). Sleep Medicine is experiencing an increase in the demand for knowledge, and is a common clinical problem encountered in psychiatry and clinical practice. Diagnosis of insomnia is $20 \%$, $8 \%$ of sleep apnea, and $18 \%$ of restless leg syndrome (RLS) (Adams, Appleton, Taylor, McEvoy, \& Antic, 2016). Patients with sleep disorders have also complained about dissatisfaction with sleep quality, sleep time and the amount of sleep received.

Sleep disorders are often one of the common problems in people with diabetes. Diabetic patients most often suffer from difficulty falling asleep. Diabetes associated with sleep disorders is a life-threatening disease with increasing prevalence. RLS is also a common occurrence, more than $50 \%$ of patients with diabetes with restless leg syndrome have poor sleep quality. RLS is the main cause of impaired sleep quality and quantity. (Mallon, Broman, \& Hetta, 2005; Modarresnia, Golgiri, Madani, Emami, \& Tanha, 2018). It not only has a major impact on sleep quality and quality of life, but also poses a significant burden on health and health-related costs (Allen, Bharmal, \& Calloway, 2011).

Aromatherapy is the use of pure essential oils from aromatic plants to help alleviate health problems and improve quality of life. Lavender is traditionally used for oral administration, it is also being employed in aromatherapy with inhalation, a, massage, dripping oil (rub on the pillow), and bathing. Lavender oil is undiluted to the skin which unlike many other essential oils used in aromatherapy (Koulivand, Ghadiri, and Gorji, 2013). Lavender oil is the most complete oil in terms of relaxation, with evidence based from fictional science (de Sousa, Almedia, Andrade, \& Andreatin, 2015). Lavender is used for stress, anxiety, fatigue, headache, migraine, insomnia and depression (Katona, Sovilj, and Petrovi, 2010). According to a study, it is found that lavender essential oil aromatherapy calms the nervous system - lowering blood pressure, heart rate and skin temperature, and allows brain wave changes to a more relaxed state (Sayorwan, et al., 2012). Lewith, Godfrey and Prescott (2005) used a 1\% lavender essential oil to measure the sleep quality of adults with mild insomnia. Another study on aromatherapy for ICU patients with severe coronary heart disease, results have shown that, patients receiving aromatherapy have improved sleep quality (Karadag, Samancioglu, Ozden, and Bakir, 2015). A study pointed to the influence of lavender aromatherapy on sleep quality and vital signs in hospitalized patients, showing significant differences in sleep quality and nocturnal blood pressure 
control (Lytle, Mwatha, \& Davis, 2014). Up until now, although nursing interventions have been effective in terms of sleep quality, there is still lack of high evidence strength results. Further research is carried out, there will certainly be a significant change in clinical practice.

With regards to resolving patients with sleep disorders, apart from giving patient sedatives and sleeping drugs to help improve sleep disorders, nursing staff should also try various methods to help promote sleep and assists in providing safe, non-invasive sleep improvement measures. Therefore, the effects of aromatherapy on sleep improvement are what nurses are striving towards.

\section{Research Question}

Is aromatherapy effective in improving sleep quality and blood glucose levels in patients with diabetes and RLS?

\section{Conceptual framework}

This study investigated the sleep quality of patients in diabetes with RLS, on whether intervention of aromatherapy measures will improve sleep problems and blood glucose level. In the experimental group, besides the researchers providing lavender essential oils, regular telephonic calls to the patient was made to assess the patients' use of essential oils and sleep conditions; the control group received general sleep hygiene education and telephonic calls to patients about their sleep conditions. The conceptual architecture of this study is shown below in figure 1 .



Figure 1. Conceptrual famework

\section{Research Design}

This study is a longitudinal experimental design to explore the effects of aromatherapy intervention on sleep quality and blood glucose in patients of 
diabetes with RLS. The independent variable was aromatherapy, and the dependent variables were sleep quality and blood glucose values. The subjects were divided into experimental group and control group, and a continuity study was carried out. The research design is shown in Table 1.

Table 1: Research Design

\begin{tabular}{lccccc}
\hline & Pretest & Aromatherapy & $1^{\text {th }}$ posttest & $2^{\text {nd }}$ posttest & $3^{\text {rd }}$ posttest \\
\hline experimental group & $\mathrm{O}_{1}$ & $\mathrm{X}$ & $\mathrm{O}_{2}$ & $\mathrm{O}_{3}$ & $\mathrm{O}_{4}$ \\
control group & $\mathrm{O}_{1}$ & & $\mathrm{O}_{2}$ & $\mathrm{O}_{3}$ & $\mathrm{O}_{4}$ \\
\hline
\end{tabular}

O1 (pretest): measure of basic information table, PSQI, and monitorblood glucose value before meal in the morning for 2days.

$\mathrm{X}=$ aromatherapy intervention.

$\mathrm{O} 2$ ( $1^{\text {st }}$ posttest), O3 ( $2^{\text {nd }}$ posttest), and O4 ( $3^{\text {rd }}$ posttest): measure of PSQI, monitor blood glucose value before meal in the morning for 2days.

\section{Study population}

This study is based on diabetes patients with RLS in the outpatient department of metabolism, using the random allocation method. The samples were taken from 900 hospital beds in the regional hospital of northern Taiwan. The inclusion criterias were 1.from the outpatient department of metabolism, patients diagnosed with diabetes and RLS by a physician; 2 . ages between 2065 years old; 3. consciousness and ability to express oneself; 4. no serious dysosmia; 5. currently not taking sleeping pills; 6. can communicate in Taiwanese and Mandarin, and after explanation, agreeing to participate in the research; and 7. PSQI assessment results > 5 points. The exclusion criterias were 1. asthmatic patients; 2 sleep apnoea and disruption; and 3. refusal to participate or disagree to participate.

\section{Sample size}

The estimated number of samples for this study was analyzed using the Mahmood (2004) statistical software (PASS 2000), which randomly assigned the order and results of random assignments that control the different attributes of the parallel group experiments. The estimation method of this study is based on the prediction of the main independent variable sleep efficiency, setting alpha value at 0.05 , power as 0.8 and effect size as 0.4 as estimation. It is estimated that in a single group, at least 22 patients are present, samples were representative, and the data were collected according to the patients who met the selection criteria.

A total of 65 patients with diabetes with RLS were screened during the study period.

17 patients using the PSI achieved a score of $\leqq 5$ points did not meet the criteria. The number of patients who met the conditions for admission was 48 patients, including 23 patients in the experimental group and 25 patients in the 
control group. After one week of tracking in the experimental group, one patient had to travel to other countries for 3 months, and voluntarily gave up participating in the study. Three people in the control group did not complete the research follow-up. Finally, there were 44 patients who were completely tracked for a 6 week period, of those, 22 patients from the experimental group, and 22 patients in the control group.

\section{Study protocol}

This study used a double blinding design as approach. Prior to the study being carried out, a researcher assistant was first trained, to ensure there was consistency in filling out of the front and back pages of questionnaires when data collection was taken. From the outpatient department of metabolism, the physician referred patients with diabetes with RLS to a researcher, from which the researcher screened the patients who met the conditions of the cases. Firstly, the researcher assistant asked each patient to explain the purpose and process of the study, and the patients or family signed the consent forms. The patients were divided into experimental group and control group by random allocation, performed by Random Allocation Software's Random Block Size. The patients were assigned to the experimental group or the control group in sequence. Both the patient and the researcher are unknown as the experimental group and the control group. The two groups filled out the patient basic information table, the PSQI Scale, and monitored the morning blood glucose level for 2 days on the first day of the case. In the second, fourth and sixth weeks, the PSQI and before breakfast blood glucose level were measured for 2 days to understand the effect of aromatherapy on sleep improvement in patients of diabetes with RLS. The experimental group was used with aromatherapy, which was, a bottle of lavender essential oil was given after the case was received, and a drop of oil both left and right was placed on the pillow every night, before going to bed; the control group did not receive any intervention measures for a total of 6 weeks. During the study period, the researcher assistant called the patient's home every 5 days to remind them, and to track them on the progress. After the study, the lavender essential oil was given to the patient. The patient in the control group was also called by the researcher every 5 days, caring about their sleep situation, in order to avoid any deviation from the experimental group. After the study, the clinical outcomes of aromatherapy were reported to the two groups.

\section{Instrument}

The PSQI was developed in 1989 by Buysse, et.al, with reference to relevant literature and contents of the previous sleep quality questionnaire. The scale was developed to test the sleep quality of clinical patients. This scale 
is a measure of the patient's sleep over the past month. Most of the time frame records the nightly sleep situation. In general, clinically, the time frame between the past 1-2 weeks is asked to distinguish between sporadic and persistent insomnia. The total score was calculated by its development scoring method, and the score ranged from 0 to 21 points. The higher the score, the worse the sleep quality, and the total score of greater than 5 points indicated that there was sleep disorder. The PSQI distinguishes between sleep problems, difficulty falling asleep, or excessive drowsiness with an accuracy of $88.5 \%$. The sensitivity was $89.6 \%$ and the specificity was $86.5 \%$. In terms of reliability, the Cronbach's $\alpha$ of the original scale was 0.83 (Buysse, Reynolds, Monk, Berman \& Kupfer, 1991). This study is based on the Mandarin PSQI by Wang (2004), which is used to obtain the consent of the original scale developer Dr. Buysse. The CVI was 0.94, changed the measurement time of the scale to one week for consistency. According the study by Lei (2003) changed the measurement time of the scale to two weeks. Our study is to confirm the effect and effective period of the aromatherapy of lavender essential oil, taking into consideration that it may take some time to assess the effective improvement of the overall sleep quality. In terms of the validity of the scale, this scale has a total score for comparative diagnosis, which can clearly distinguish the quality of sleep. In this study, the PSQI had a cronbach's $\alpha$ of 0.78 . The blood glucose monitor is an essential monitoring tool for diabetic patients. The patient takes the blood glucose reading at home. This research laboratory uses a simple blood glucose test machine of the same brand, which is executed by the patient at home, and is corrected once after each use.

\section{Data analysis}

After investigating the questionnaire data obtained by the researchers. The statistical method were used with percentage, Chi Square and ANOVA. The significance level was set to $\mathrm{p}<0.05$. In this study, sleep latency, individual subjective sleep quality, daytime dysfunction, sleep disturbance, and blood glucose values were corrected for the interaction between repeatedly measured variables using a generalized liner mixed-effects model (Mixed effects GLMs). The statistical strength of subsequent measurements was corrected to accurately assess the important effects of aromatherapy on and between groups, and within the group under relevant factors that control repeated observations of the same patient.

\section{Result}

\section{Demographic information}

The average age of the experimental group was $52.82 \pm 7.532$ and the control group was $51.68 \pm 8.812$, of which were mostly female $(61.3 \%)$ and 
married (93.2\%). There were 52.3\% high schools of education levels; occupation distribution was equal- half had jobs and of the other half were jobless; most of the participants were non-smokers $(81.8 \%)$ and non-drinkers $(90.9 \%)$; tea $(79.5 \%)$ and coffee $(86.4 \%)$ were mostly not consumed or occasionally consumed; most participants did not suffer from depression (75\%); there were $65.9 \%$ patients with $\mathrm{BMI}>25$; nocturia $(59.1 \%$ ) were between the two groups; most participants did not exercise regularly (59.1\%). According to the analysis results of Chi-square test and Independent t test, there was no statistically significant difference between the experimental group and the control group based on the comparison of basic data $(\mathrm{P}>0.05)$. The homogeneity of the group is high.

With the seven domains of the PSQI, Table 2 shows the results of the pre-test, the patients in the experimental group and the control group were consistent with the worst of the first three items in the PSQI and its subscale, before aromatherapy intervention was introduced. In pretest, the physiological blood glucose level, the average score of the experimental group and the control group were no statistically significant difference between the two groups.

Table 2. Diabetes with RLS Pre-measurement of Pittsburgh Scale Comparison of Sleep Quality Distribution and Blood Glucose Value

\begin{tabular}{lllll}
\hline & $\begin{array}{c}\text { experimental group } \\
\text { Mean } \pm \text { SD }\end{array}$ & $\begin{array}{c}\text { Control group } \\
\text { Mean } \pm \text { SD }\end{array}$ & T & p \\
\hline Subjective sleep quality & $2.09 \pm 0.75$ & $1.77 \pm 0.69$ & 1.47 & 0.15 \\
sleep latency & $2.41 \pm 0.73$ & $2.05 \pm 0.79$ & 1.59 & 0.12 \\
sleep duration & $1.73 \pm 0.88$ & $1.09 \pm 0.92$ & 2.34 & $0.02^{*}$ \\
sleep efficiency & $1.23 \pm 1.19$ & $0.55 \pm 0.67$ & 2.34 & $0.02^{*}$ \\
sleep disturbance & $1.55 \pm 0.60$ & $1.32 \pm 0.57$ & 1.30 & 0.20 \\
daytime dysfunction & $1.82 \pm 0.59$ & $1.68 \pm 0.89$ & 0.60 & 0.55 \\
overall sleep quality & $10.59 \pm 2.15$ & $8.64 \pm 2.22$ & 2.54 & $0.02^{*}$ \\
Blood sugar & $186.23 \pm 61.75$ & $168.27 \pm 55.47$ & 1.02 & 0.32 \\
\hline \multicolumn{2}{c}{$\mathrm{P}<0.05^{*} ; \mathrm{p}<0.01^{* *}$} & & &
\end{tabular}

\section{Results of Aromatherapy intervention in two groups on sleep quality Differences between the two groups in aromatherapy intervention for sleep latency, subjective sleep quality, sleep disturbance, and daytime dysfunction}

Table 2 shows that the patients in the experimental group and the control group were tested by independent $t$ test in terms of subjective sleep quality, sleep latency, sleep disturbance, daytime dysfunction and blood glucose level. According to the independent t test, there was no statistically significant difference, indicating that the two groups were highly homogenous. Table 3 shows the subjective sleep quality, sleep latency, sleep disturbance, and daytime dysfunction of the two groups of patients in the pre- 
test, the first post-test, the second post-test, and the third post-test. The interaction was detected by ANOVA. Daytime dysfunction had no interaction $(\mathrm{p}>0.05)$, and the remaining variables showed interaction $(\mathrm{p}<0.05)$. Therefore, the general linear mixed-effect model (GLMM) analysis was used, and the interaction between the repeated measures of the variables was corrected to detect the difference between the two groups of patients after the aromatherapy intervention; according to table 2, there were statistically significant differences in sleep hours, sleep efficiency, and overall sleep quality between the two groups $(\mathrm{P}<0.05)$.

\section{Differences in time-dependent changes between two groups of aromatherapy intervention on sleep latency}

Differences in time-dependent changes between two groups of aromatherapy intervention on sleep latency. The difference between the preand post-test was measured by paired-sample $t$ test. The changes in sleep latency of the two groups before and after aromatherapy intervention are shown in Figure 3, showing the trend of sleep latency. With observation and time tracking, there was a specific interaction between group and time (table 3).After 4 weeks of intervention, the effect $\beta$ value of sleep latency was 0.59 $(\mathrm{p}<0.05)$, the effect $\beta$ value was $-0.50(\mathrm{p}=0.05)$ after 4 weeks of intervention. After 6 weeks, the effect of $\beta$ value was $-0.64(\mathrm{p}=0.01)$ (table 4$)$. The intervention of aromatherapy, the experimental group showed significant differences in the sleep latency at the second week in comparison with the control group, and continued until the sixth week. 
Table 3. Results of Aromatherapy intervention in two groups on sleep quality

\begin{tabular}{|c|c|c|c|c|c|c|c|c|c|c|}
\hline & \multicolumn{4}{|c|}{ experimental group $($ mean $\pm S D)$} & \multicolumn{4}{|c|}{ Control group (mean $\pm \mathrm{SD}$ ) } & \multirow{2}{*}{$\alpha$} & \multirow{2}{*}{$\mathrm{p}$} \\
\hline & Pre-test & $1^{\text {st }}$ post-test & $2^{\text {nd }}$ post-test & $3^{\text {rd }}$ post-test & Pre-test & $1^{\text {st }}$ post-test & $2^{\text {nd }}$ post-test & $3^{\text {rd }}$ post-test & & \\
\hline sleep latency & $2.41 \pm 0.73$ & $1.82 \pm 0.78$ & $1.86 \pm 0.89$ & $1.77 \pm 0.87$ & $2.05 \pm 0.79$ & $1.91 \pm 0.87$ & $2.00 \pm 0.69$ & $2.05 \pm 0.72$ & 7.16 & $0.01 * *$ \\
\hline $\begin{array}{l}\text { subjective sleep } \\
\text { quality }\end{array}$ & $2.09 \pm 0.75$ & $1.41 \pm 0.59$ & $1.28 \pm 0.53$ & $1.27 \pm 0.46$ & $1.77 \pm 0.69$ & $1.36 \pm 0.73$ & $1.41 \pm 0.73$ & $1.59 \pm 0.67$ & 8.99 & $0.01 * *$ \\
\hline $\begin{array}{l}\text { daytime } \\
\text { dysfunction }\end{array}$ & $1.82 \pm 0.59$ & $1.68 \pm 0.84$ & $1.41 \pm 0.59$ & $1.41 \pm 0.50$ & $1.68 \pm 0.89$ & $1.50 \pm 0.67$ & $1.46 \pm 0.74$ & $1.55 \pm 0.74$ & 1.98 & 0.17 \\
\hline sleep disturbances & $1.55 \pm 0.60$ & $1.18 \pm 0.59$ & $1.14 \pm 0.56$ & $1.09 \pm 0.43$ & $1.32 \pm 0.57$ & $1.27 \pm 0.55$ & $1.27 \pm 0.55$ & $1.27 \pm 0.55$ & 7.07 & $0.01 * *$ \\
\hline Blood sugar & $186.22 \pm 61.75$ & $145.00 \pm 47.04$ & $149.00 \pm 42.48$ & $149.18 \pm 51.55$ & $168.27 \pm 55.46$ & $166.22 \pm 41.34$ & $170.36 \pm 46.00$ & $157.22 \pm 47.36$ & 3.32 & $0.05^{*}$ \\
\hline
\end{tabular}

$\mathrm{P}<0.05^{*} ; \mathrm{p}<0.01^{* *} ; 1^{\text {st }}$ post-test indicates on 2 weeks after intervention; $2^{\text {nd }}$ post-test indicates on 4 weeks after intervention; $3^{\text {rd }}$ post-test indicates on 6 weeks after intervention.



Figure 3. Comparison of group differences in sleep latency

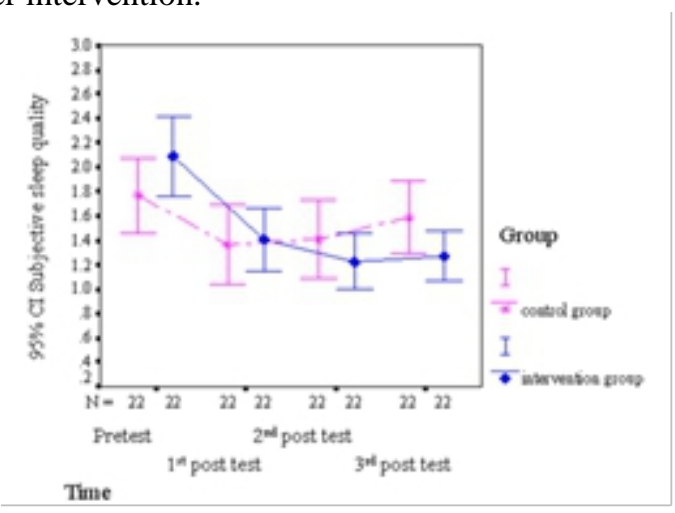

Figure 4. Comparison of group differences in sleep quality 
Table 4. Differences between the two groups in aromatherapy intervention for sleep latency, subjective sleep quality, improvement of sleep

\begin{tabular}{|c|c|c|c|c|c|c|c|c|c|c|c|c|c|c|c|}
\hline & \multicolumn{3}{|c|}{ sleep latency } & \multicolumn{3}{|c|}{ subjective sleep quality } & \multicolumn{3}{|c|}{ daytime dysfunction } & \multicolumn{3}{|c|}{ sleep disturbances } & \multicolumn{3}{|c|}{ Blood sugar } \\
\hline & $\beta$ & S.E. & $\mathrm{p}$ & $\beta$ & S.E. & $\mathrm{p}$ & $\beta$ & S.E. & $\mathrm{p}$ & $\beta$ & S.E. & $\mathrm{p}$ & $\beta$ & S.E. & $\mathrm{p}$ \\
\hline \multicolumn{16}{|l|}{ group } \\
\hline $\begin{array}{l}\text { ( experimental group vs. } \\
\text { control group ) }\end{array}$ & 0.36 & 0.23 & 0.12 & -0.32 & 0.22 & 0.42 & 0.14 & 0.23 & 0.55 & 0.28 & 0.18 & 0.20 & 17.95 & 17.70 & 0.32 \\
\hline \multicolumn{16}{|l|}{ time } \\
\hline $1^{\text {st }}$ post-test vs. pre-test & -0.14 & 0.17 & 0.44 & -0.41 & 0.32 & $0.01 *$ & -0.18 & 0.17 & 0.29 & -0.45 & 0.09 & 0.65 & -2.05 & 8.85 & 0.83 \\
\hline $2^{\text {nd }}$ post-test vs. pre-test & -0.05 & 0.17 & 0.79 & -0.36 & 0.17 & $0.04 *$ & -0.23 & 0.17 & 0.20 & -0.45 & 0.12 & 0.70 & 2.36 & 9.13 & 0.80 \\
\hline $3^{\text {rd }}$ post-test vs. pre-test & 0.00 & 0.15 & 1.00 & -0.18 & 0.14 & 0.21 & -0.32 & 0.14 & 0.35 & -0.45 & 0.10 & 0.65 & -11.05 & 1.00 & 0.30 \\
\hline \multirow{2}{*}{\multicolumn{16}{|c|}{$\begin{array}{l}\text { group *time ( experimental } \\
\text { group vs. control group ) }\end{array}$}} \\
\hline & & & & & & & & & & & & & & & \\
\hline $1^{\text {st }}$ post-test vs. pre-test & -0.59 & 0.24 & $0.03 *$ & 0.27 & 0.20 & 0.18 & & & & -0.32 & 0.13 & 0.07 & -39.18 & 12.51 & $0.02 *$ \\
\hline $2^{\text {nd }}$ post-test vs. pre-test & -0.50 & 0.24 & $0.05 *$ & -0.50 & 0.24 & $0.04 *$ & & & & -0.36 & 0.16 & $0.04 *$ & -39.59 & 12.91 & $0.02 *$ \\
\hline $3^{\text {rd }}$ post-test vs. pre-test & -0.64 & 0.21 & $0.01 *$ & -0.64 & 0.20 & $0.00 * *$ & & & & -0.41 & 0.13 & $0.02 *$ & -26.00 & 14.13 & 0.10 \\
\hline
\end{tabular}

$\mathrm{P}<0.05^{*} ; \mathrm{p}<0.01^{* *} ; 1$ st post-test indicates on 2 weeks after intervention; 2 nd post-test indicates on 4 weeks after intervention; 3rd post-test indicates on 6 weeks after intervention. 
Differences in time-dependent changes between two groups of aromatherapy intervention on subjective sleep quality

Differences in time-dependent changes between two groups of aromatherapy intervention on subjective sleep quality. The subjective sleep quality of the two groups of patients before and after the intervention of aromatherapy is shown in Figure 4. In the experimental group, the subjective sleep quality of the first post-test was worse than that of the control group, and the estimated value $\beta$ was $0.27(\mathrm{p}=0.18)$. With continuous observation and time tracking, the group and the time show a specific interaction (table 3). In the experimental group, the score of the second post-test was compared with that of the pre-test score, which fared better than that of the control group. The estimated value $\beta$ was -0.50 ( $\mathrm{p}=0.04)$. Patients in the third post-test group was still better than the control group, and the estimated value $\beta$ was $-0.64(\mathrm{p}=0.00)$ (table 4). Continued observation and follow-up time after aromatherapy intervention showed that the subjective sleep quality test group had significant differences compared with the control group during fourth and sixth week.

\section{Differences in time-dependent changes between two groups of aromatherapy intervention on sleep disturbances}

Differences in time-dependent changes between two groups of aromatherapy intervention on sleep disturbances. With continuous observation and time tracking, the group and time shows a specific interaction as seen in Figure 5. In the experimental group, although the sleep disturbance in the first post-test was better than that in the control group, the estimated value $\beta$ was $-0.32(\mathrm{p}=0.07)$. In the experimental group, the second post-test score and the third post-test score were significantly better than the pre-test score, which was better than the control group. The estimated value $\beta$ was $0.36(\mathrm{p}=0.04)$ and $\beta-0.41(\mathrm{p}=0.02)$ (table 4$)$. There are statistically significant differences. Observations with follow-up time after aromatherapy intervention showed that the sleep disturbances in the experimental group were significantly different from the control group at fourth and sixth week.

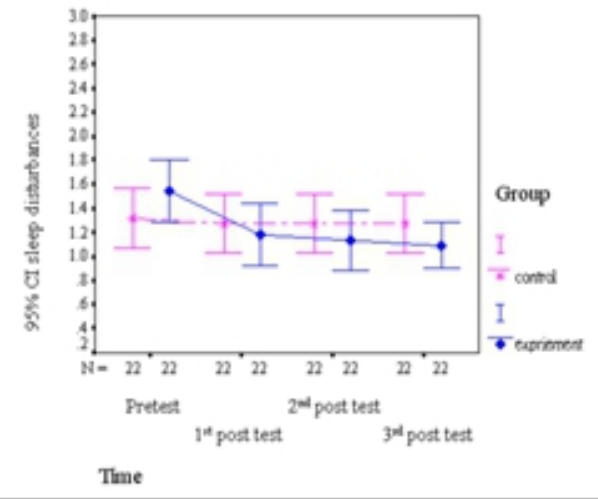

Figure 5. Comparison of group differences in sleep disturbance 


\section{Differences in time-dependent changes between two groups of aromatherapy intervention on blood glucose values}

As seen in Figure 6, the pre-test blood glucose level in the experimental group was higher than that of the control group. The blood glucose level of the first post measurement of the experimental group was lower than that of the control group. The estimated value $\beta$ was -39.18 ( $p=0.02$ ). In the second post-measurement compared with the pre-measured value, the results fared slightly better than the control group, with the estimated value $\beta$ at -39.59 $(\mathrm{p}=0.02)$, showing a significant change. The third post-test was compared with the pre-test. The patients in the experimental group fared better than the patients in the control group. The estimated value $\beta$ was $-26.00(\mathrm{p}=0.10)$ (table 4 ), which was not statistically significant. Observations with follow-up time after aromatherapy intervention showed that the blood glucose test group was significantly different from the control group at second and fourth week.

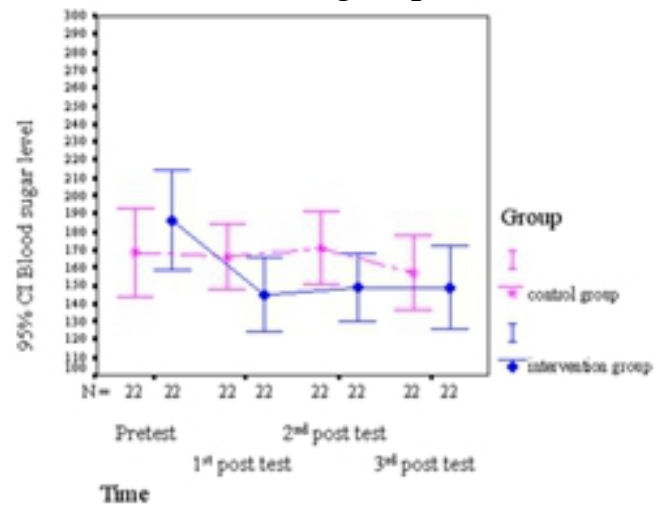

Figure 6. Comparison of group differences in blood sugar

\section{Pre-test and post-test changes in patient group before and after comparing differences in sleep hours, sleep efficiency, and overall sleep quality}

The sleep quality of the experimental group was measured at two time points, pre-test and third post-test. The paired t test (Paired-sample $t$ test) was used to analyze the sleep time $t=2.41(p<0.05)$, and the sleep efficiency $t=2.03$ $(\mathrm{P}>0.05)$, overall sleep quality $\mathrm{t}=7.26(\mathrm{p}=0.00)$. There was a statistically significant difference in sleep hours and overall sleep quality between the groups $(\mathrm{P}<0.05)$. The control group measured at pre-test and third post- test showed that the sleep time was $t=0.00(p=1.00)$, the sleep efficiency was $t=-$ $0.94(\mathrm{p}=0.36)$, and the overall sleep quality was $\mathrm{t}=2.10(\mathrm{p}=0.05)$. There was only a statistically significant difference in overall sleep quality between the groups $(\mathrm{P}<0.05)($ Table 5). 
Table 5. Differences in sleep hours, sleep efficiency, and overall sleep quality changes in the group

\begin{tabular}{llccccc}
\hline & & $\begin{array}{c}\text { Pretest } \\
\text { Mean } \pm \text { SD }\end{array}$ & $\begin{array}{c}3^{\text {rd }} \text { posttest } \\
\text { Mean } \pm \text { SD }\end{array}$ & $\begin{array}{c}\text { Differences of } \\
\text { Mean } \pm \text { SD }\end{array}$ & $\mathrm{t}$ & $\mathrm{p}$ \\
\hline $\begin{array}{l}\text { experimental } \\
\text { group }\end{array}$ & sleep duration & $1.73 \pm 0.88$ & $1.32 \pm 1.00$ & $-0.41 \pm 0.75$ & 2.41 & $0.03^{*}$ \\
& $\begin{array}{l}\text { sleep efficiency } \\
\text { overall sleep }\end{array}$ & $1.23 \pm 1.19$ & $0.68 \pm 0.89$ & $0.55 \pm 1.26$ & 2.03 & 0.06 \\
& $10.56 \pm 2.15$ & $6.91 \pm 2.31$ & $3.68 \pm 2.38$ & 7.26 & $0.00^{* *}$ \\
\hline $\begin{array}{l}\text { quality } \\
\text { group }\end{array}$ & sleep duration & $1.09 \pm 0.92$ & $1.09 \pm 0.92$ & $0.00 \pm 0.00$ & 0.00 & 1.00 \\
& $\begin{array}{l}\text { sleep efficiency } \\
\text { overall sleep }\end{array}$ & $0.55 \pm 0.67$ & $0.73 \pm 0.77$ & $-0.18 \pm 0.90$ & -0.94 & 0.36 \\
& quality & $8.64 \pm 2.22$ & $7.95 \pm 2.40$ & $0.68 \pm 1.52$ & 2.10 & $0.05^{*}$ \\
\hline
\end{tabular}

$\mathrm{P}<0.05^{*} ; \mathrm{p}<0.01^{* *} ; 3$ rd post-test indicates on 6 weeks after intervention.

\section{Discussion}

\section{Discussion and Analysis of Demographic Information}

The average age of all subjects in the study was 52.2 years, $38.6 \%$ and $61.4 \%$ for men and women, respectively. Based on the clinical research results, outpatients with type 2 diabetes associated sleep problems (PSQI $\geqq 6$ ), the mean age was 69.9 years, $24.4 \%$ for men and $75.6 \%$ for women (Lopes et al, 2005). Our study shows that the subjects' ages are different from those; however the ratio of male to female is similar. The reason that our study reflected a younger age group may be that, the study subjects were limited to 18-65 years of age, thus the results are of a younger age group than that of other studies.

Our study of nocturia patients accounted for $59.1 \%$. According to Pearson's product correlation coefficient, results showed that nocturia was associated with sleep disturbance of PSQI ( $\mathrm{p}=0.05)$, and it was the only factor positively related to sleep disturbance, however, no correlation with daytime dysfunction. There was a significant association between nocturia and daytime dysfunction in male patients or patients under 65 years of age (Shao, Wu, Hsu, Change, Wange, \& Tam, 2016). Nocturia is one of the causes of sleep disorders. However, there is currently no definitive assessment of the most relevant treatment for nocturia (Ancoli-Israel, Bliwise, \& Nørgaard, 2011). Nocturia and sleep quality, sleep disturbance, and daytime dysfunction still rely on in-depth discussion and research to better understand the problems between nocturia and sleep, in order to tackle the problem thereof.

Studies have shown that the mechanism of association between sleep quality and Body Mass Index (BMI) is unclear (Hung et al., 2013). Studies have also shown that people with $\mathrm{BMI} \geq 25$, there were $51 \%$ scored a PSQI $>$ 5 , sleep quality is poor, and sleep disorders are associated with overweight after age and gender control (Vargas, Flores, and Robles, 2014). However, 
based on our study, there were $69.9 \%$ patients with a BMI $>25$, the statistics based on Pearson's product correlation coefficient shows that there is no correlation between BMI and any domain of PSQI.

\section{Diabetes with RLS and sleep quality}

Lin, Tsai, \& Yeh (2016) stated that the average sleep time of quality sleep in diabetic patients is 7.2 hours, of which $35.1 \%$ of participants have a sleep duration of less than 7 hours. According to Sirdhar (2003), an average sleep time of 7.2 hours; all participants indicated that they wished to sleep an additional 1.8 hours per night. From our study, the average sleep time of the study subjects was 5.75 hours, which was slightly less than that of other studies. The reason may be that, the study population is not just simply based on diabetes alone, and RLS may be the reason for the patient to be sleep deprived. Diabetes with RLS sleep quality is worse than that of patients with diabetes alone, and may be the main cause of sleep disruption in these patients.

The participants had varying degrees of poor sleep quality in our study. The overall sleep quality of the PSQI was 9.55, with a minimum score of 6 and a maximum score of 15 points. A study presented an average PSQI score of 8.3 and $71 \%$ of patients with a score of $>5$. They also presented average amount of self-reported sleep of diabetic patients was 6.10 hours, the mean difference between preferred and actual weekday sleep was $1.83 \pm 2.01$ hours. There is significant difference in actual sleep hours, representing the presence of sleep debt in diabetic patients (Vigg, Vigg, and Vigg, 2003). Compared with above study, our study scored a much higher PSQI average score, representing poor sleep quality. This may be due to the fact that our study screened diabetic patients with RLS with a PSQI > 5, and the two other comparative study cases included sleep status in diabetic patients, with or without RLS.

In our study, according to the seven components of PSQI, the sleep quality of participants scored the worse in sleep latency, which means long time in attempting to fall asleep. It has been pointed out in the literature that people with diabetes are most often suffering from difficulty falling asleep (Malloney, Browan \& Hetta, 2005; Gottlieb, Punjabi, Newman, Resnicj, Redline, Baldwin \& Nieto, 2005). Based on the study by Skomto, Ludwig, and Salamon (2001), patients with Type 2 diabetes with RLS, participants who experienced insomnia showed that $42.9 \%$ had difficulty falling asleep. Based on the above findings, it is consistent with the results of our study that difficulty falling asleep is one of the major sleep problem in diabetic patients, as well as daytime dysfunction. The low quality of sleep in patients with diabetes with RLS is indeed worthy of attention. 


\section{The effect of lavender essential oil on sleep quality}

Two articles in the systematic literature show that lavender oil has small to medium benefits on sleep quality (Fismer, and Pilkington, 2012). For people with mild sleep disorders, consider inhaling essential oils (Lillehei, and Halcon, 2014). Our study uses 1\% lavender essential oil, a natural aromatherapy method for insomniac diabetic patients with RLS. According to the results of the PSQI, the overall sleep quality continued to improve, down to 3.68 points in the sixth week, and the overall sleep quality improved. A study, aimed at the average college students' intervention on lavender essential oil for two weeks, showed even better sleep quality, and stated that waking up felt more refreshing than ever before (Lillehei, Halco' n, Savik, And Reis, 2015). The sleep quality using PSQI was measured, and the overall sleep quality improved by 2.5 points. It can be seen that aromatherapy is a relatively simple intervention that can be promoted for improving the sleep quality of patients.

Sleep latency is the major sleep problem of patients in the experimental or control group in this study. The sleep latency was the earliest configuration of the PSQI after the intervention of $1 \%$ lavender essential oil in the experimental group, and continued until the sixth week. It may come from the use of lavender essential oils for calming, for promoting sleep, quick sleep, and calmness (Cauffield, 2001). Many human studies support their effectiveness in different neurological and psychological disorders, has indeed, shown a psychological impact (Koulivand, Ghadiri, and Gorji, 2013). The subjective sleep quality of our study is based on personal subjective feeling. After the intervention of aromatherapy, the patients in the experimental group can feel the improvement of sleep quality, and also the effect of aromatherapy on psychology.

The results of sleep disturbance in our study, suggested pain as the main problem of sleep disorders due to there were $100 \%$ patients with pain. Lavender aroma is a mild anesthetic with analgesic and anti-inflammatory properties (Shenefelt, 2005). Our study suggests that improvements in sleep disturbance may be related to the efficacy of lavender essential oils. However, hence the result of this study can be used as one of the research directions in the future.

After the intervention of sleep efficiency aromatherapy, there was no significant difference up until the sixth week. The reason may be that sleep efficiency may not be a problem in patients with diabetes and RLS, and it is known from the results of the above-mentioned sleep latency that the role of aromatherapy lavender essential oil is most beneficial for guiding sleep. There has been no research to explore the mental state of waking up during sleep when using aromatherapy; therefore, whether the time spent awake in bed is 
related to aromatherapy, this issue deserves further investigation in future research.

\section{The effect of lavender essential oil on blood glucose}

Aromatic essential oils improve blood glucose tolerance (Jones, and Kassity, 2001); Lavandula stoechas essential oils significantly prevent against increase in blood glucose and decrease antioxidant enzyme activities induced by aloxan treatment. Subacute essential oil treatment induces a decrease in lipid peroxidation and an increase in antioxidant enzyme activity (Sebai, Selmi, Rtibi, Souli, Gharbi \& Sakly, 2013). In our study, 1\% of lavender essential oil improved blood glucose levels in the second week after intervention, and continued until the fourth week, showing the benefits of lavender essential oil on blood sugar in the beginning stage. In the late stage, the blood sugar level maintained the same level as the fourth week but did not have significant on sixth week. However, we suggest that should go further into further explore.

\section{Conclusion}

The purpose of this study was to investigate the effects of aromatherapy on the improvement of sleep quality and their effects on physiological blood glucose. The important result of integration is poor sleep quality in patients of diabetic with RLS, including moderately unsatisfactory subjective sleep quality, longer sleep latency, shorter sleep hours, moderate sleep disturbance, and moderate daytime dysfunction. In the experimental group, patients of diabetes with RLS improved their sleep latency in the second week after the intervention of aromatherapy, and continued to improve up until the sixth week; fourth week showed an improvement on subjective sleep quality and sleep disturbance. In the aromatherapy experimental group, patients of diabetes with RLS shows decrease in their blood glucose levels in the second week.

\section{Application and Suggestions}

From our study, sleep problems in diabetic patient with RLS is a common occurrence, mainly caused by difficulty falling asleep. However, at present, sleep problems for diabetic patients with RLS is mostly treated with sleeping pills. This problem deserves the attention of nursing staff, the development and provision of safe, non-invasive methods to promote and provide improvement measures, in order to improve the quality of nursing care. This study demonstrates that the intervention of aromatherapy can immediately and continuously improve the subjective sleep quality, sleep latency, and sleep disturbance in patients of diabetes with RLS in the experimental group; improvement on actual sleep hours and overall sleep 
quality of the experimental group at night. The results of this study can be applied to clinical nursing practice. It is recommended that clinical nurses can establish the care norms and basis for aromatherapy for diabetic patients, in order to further develop a comprehensive care model for diabetic patients.

\section{Limitations}

This study only accepted cases in regional teaching hospitals in north of Taiwan. In the future, research can be carried out in hospitals in different regions, therefore, increasing the number of patients from different ethnic groups. The study of sleep quality in this study focused on measurement of subjective sleep perception and state of sleep, but not for objective physiological indicators. Future research should incorporate more objective measurements in order to match objective instrument or physiological response measurements, for more scientific and more detailed verification.

\section{References:}

1. Adams, R., Appleton, S., Taylor, A., McEvoy, D., \& Antic, N. (2016). Report to the sleep health foundation 2016 sleep health survey of Australian adults. The University of Adelaide. The Adelaide Institute for Sleep Health. P2-48. Retrieved on February 8, 2018, from: http://www.sleephealthfoundation.org.au/pdfs/surveys/SleepHealthFo undation-Survey.pdf

2. Allen, R. P., Picchietti, D., Hening W. A., Trenkwalder, C., Walters, A.S., \& Montplaisi, J. (2003). Restless legs syndrome: diagnostic criteria, special considerations, and epidemiology: a report from the restless legs syndrome diagnosis and epidemiology workshop at the National Institutes of Health. Sleep Medicine, 4(2), 101-119. doi: 10.1016/S1389-9457(03)00010-8.

3. Ancoli-Israel, S., Bliwise, D.L., \& Nørgaard, J.P. (2011). The effect of nocturia on sleep. Sleep Medicine Reviews. 15(2), 91-97. doi: 10.1016/j.smrv.2010.03.002.

4. Buysse, D.J., Reynolds, C.F., Monk, T.H., Berman, B.R., \& Kupfer, D.J. (1989). The Pittsburg Sleep Quality Index: a new instrument for psychiatric practice and research. Psychiatry Research, 28, 193-312.

5. Buysse, D.J., Reynolds III, C.F., Monk, T.H., Hoch, C.C., Yeager, A.L., \& Kupfer, D.J. (1991). Quantification of subjective sleep quality in healthy elderly men and woman using the Pittsburgh Sleep Quality Index (PSQI). Sleep, 14(4), 331-338.

6. Cauffield, J.S. (2001). Supplement used to treat sleep disorders. U.S. Pharmacist, 26(6). Retrieved November 5, http://www.uspharmacist.com/index.asp?show=article\&page=8_1627 .htm. 
7. de Sousa, D.P., de Almeida Soares Hocayen, P., Andrade, L.N., \& Andreatini, R. (2015). A systematic review of the anxiolytic-like effects of essential oils in animal models. Molecules, 20(10), 1862018660. doi: 10.3390/molecules201018620.

8. Fismer, K.L. \& Pilkington, K. (2012). Lavender and sleep: a systematic review of the evidence. European Journal of Integrative Medicine, 4(4), e436-e447. doi: 10.1016/j.eujim.2012.08.001.

9. Gottlieb, D.J., Punjabi, N.M., Newman, A.B., Resnick, H.E., Redline, S., Baldwin, C.M., \& Nieto, F.J. (2005). Association of sleep time with diabetes mellitus and impaired glucose tolerance. Archives of Internal Medicine, 165, 863-868. doi: 10.1001/archinte.165.8.863.

10. Hung, H.C., Yang, Y.C., Ou, H.Y., Wu, J.S., Lu, F.H., \& Chang, C.J. (2013). The association between self-reported sleep quality and overweight in a Chinese population. Obesity, 21(3), 486-492. doi: 10.1002/oby.20259.

11. Jones, J.N., \& Kassity, N. (2001). Varieties of alternative experience: Complementary care in the neonatal intensive care unit. Clinical Obstetrics and Gynecology, 44(4), 750-768.

12. Karadag, E., Samancioglu, S., Ozden, D., and Bakir, E. (2015). Effects of aromatherapy on sleep quality and anxiety of patients. British Association of Critical Care Nurses, 22(2), 105-112. doi: 10.1111/nicc.12198.

13. Katona, J.M., Sovilj, V.J. \& Petrovi, L.B. (2010). Microencapsulation of oil by polymer mixture-ionic surfactant interaction induced coacervation. Carbohydrate Polymers, 79, 563-570. doi:10.1016/j.carbpol.2009.09.007.

14. Koulivandm, P.H., Khaleghi Ghadiri, M., \& Gorji, A. (2013). Lavender and the nervous system. Evidence-Based Complementary and Alternative Medicine, Article ID 681304, 11-10. doi: 10.1155/2013/681304.

15. Lei, C.W., \& Lin, S.L. (2003). The relationship between physical activity and sleep quality of middle aged women. Journal of Health Education, 20, 151-169.

16. Lewith, G.T., Godfrey, A.D., \& Prescott, P. (2005). A single-blinded, randomized poilt study evaluating the aroma of lavandula augustifolia as a treatment for mild insomnia. Journal of Alternative and Complementary Medicine, 11(4), 631-637. doi: 10.1089/acm.2005.11.631.

17. Lillehei, A.S., \& Halcon, L.L. (2014). A systematic review of the effect of inhaled essential oils on sleep. Journal of Alternative Complementary Medicine, 20(6), 441-51. doi: 10.1089/acm.2013.0311. 
18. Lillehei, A.S., Halco’ n, L.L., Savik, K., \& Reis, R. (2015). Effect of inhaled lavender and sleep hygiene on self-reported sleep issues: a randomized controlled trial. The Journal of Alternative and Complementary Medicine, 21(7), 430-438. doi: 10.1089/acm.2014.0327.

19. Lin, C.L., Tsai, Y.H., \& Yeh, M.C. (2016). Associations between sleep duration and type 2 diabetes in Taiwanese adults: a population-based study. Journal of the Formosan Medical Association, 115, 779-785. doi: 10.1016/j.jfma.2016.01.013.

20. Lopes, L.A., Lins, Cde. M., Adeodato, V.G., Quental, D.P., de Bruin, P.F., Montenegro, R.M.Jr, \& de Bruin, V.M. (2005). Restless legs syndrome and quality of sleep in type 2 diabetes. Diabetes Care, 28(11), 2633-2636. doi: org/10.2337/diacare.28.11.2633.

21. Lytle, J, Mwatha, C., \& Davis, K.K. (2014). Effect of lavender aromatherapy on vital signs and perceived quality of sleep in the intermediate care unit: a pilot study. American Journal of Critical Care, 23(1), 24-29. doi: 10.4037/ajcc2014958.

22. Mahood, S. (2004). Random allocation software for parallel group randomized trials. BMC Medical Research Methodology, 4(26), doi: 10.1186/1471-2288-4-26.

23. Mallon, L., Broman, J-E., \& Hetta, J. (2005). High incidence of diabetes in men with sleep complaints or short sleep duration: a 12year follow-up study of a middle-aged population. Diabetes Care, 28(11), 2762-2767. doi: 10.2337/diacare.28.11.2762.

24. Modarresnia. L., Golgiri. F., Madani. N.H., Emami. Z., \& Tanha. K. (2018). Restless legs syndrome in Iranian people with type 2 diabetes mellitus: the role in quality of life and quality of sleep. Journal of Clinical Sleep Medicine, 14(2), 223-228. doi: 10.5664/jcsm.6938.

25. Sayorwan, W., Siripornpanich, V., Piriyapunyaporn, T., Hongratanaworakit, T., Kotchabhakdi, N., and Ruangrungsi., N. (2012). The effects of lavender oil inhalation on emotional states, autonomic nervous system, and brain electrical activity. Journal of Medical Association of Thailand, 95(4), 598-606.

26. Sebai,H., Selmi, S., Rtibi, K., Souli, A., Gharbi, N., \& Sakly, M. (2013). Lavender (Lavandula stoechas L.) essential oils attenuate hyperglycemia and protect against oxidative stress in alloxan-induced diabetic rats. Lipids in Health and Disease, 12(189), 1-9. doi: 10.1186/1476-511X-12-189.

27. Shao, I.H., Wu, C.C., Hsu, H.S., Chang, S.C., Wang, H.H., Chuang, H.C., \& Tam, Y.Y. (2016). The effect of nocturia on sleep quality and daytime function in patients with lower urinary tract symptoms: a 
cross-sectional study. Clinical Interventions in Aging, 11, 879-885. doi: 10.2147/CIA.S104634. eCollection 2016.

28. Shenefelt, P.D. (2005). Complementary psychocutaneous therapies in dermatology. Dermatologic Clinics, 23, 723-734. doi: 10.1016/j.det.2005.05.011.

29. Sirdhar, G. (2003). Sleep in type 2 diabetes. The Journal of the Association of the Physicians of India, 51, 479-481.

30. Skomto, P.P., Ludwig, S., \& Salamon, E. (2001). Sleep complaints and restless legs syndrome in adult type 2 diabetes. Sleep Medicine, 2(5), 417-422.

31. Talih, F., Ajaltouni, J., \& Kobeissy, F. (2016). Restless leg syndrome in hospitalized psychiatric patients in Lebanon: a pilot study. Neuropsychiatric Disease and Treatment. 12, 2581-2586. doi: 10.2147/NDT.S116271.

32. The American Psychiatric Association (APA). (2013). Diagnostic and statistical manual of mental disorders, 5th ed. Washington, DC. https://doi.org/10.1176/

33. appi.books.9780890425596.

34. Vargas, P.A., Flores, M., \& Robles, E. (2014). Sleep quality and body mass index in college students: the role of sleep disturbances. Journal of American College Health. 62(8), 534-541. doi: 10.1080/07448481.2014.933344.

35. Vigg, A., Vigg, A., \& Vigg, A. (2003). Sleep in Type 2 Diabetes. Journal of the Association of Physicians of India, 51, 479-481.

36. Wang, R.C. (2004). A comparison of the effect of chronic pain on mood states and quality of sleep between patients with cancer pain and patients with daily headache (Unpublished master's thesis). Taipei: Institute of Nursing, Taipei Medical University. 